\title{
Interplay between performance measurement and management, employee engagement and performance
}

\begin{abstract}
Purpose - The literature recognises the importance of the interplay between performance measurement, performance management, employee engagement and performance. However, the nature of this phenomenon is not well understood. Analysis of the literature reveals two dimensions of organisational control, technical and social, that are used to develop a conceptual framework for studying this phenomenon.
\end{abstract}

Methodology - We conducted explorative action research involving pilot and control groups from two departments of a UK bank.

Findings - We show that an intervention on the social-controls has led to changes in technicalcontrols of the performance measurement system resulting in significant improvement in employee engagement and performance.

Limitations - The research was undertaken with two cases from a single organisation. Further finegrained, longitudinal research is required to fully understand this phenomenon in a wider range of contexts.

Practical implications - Our work contributes to the theory on performance measures and gives guidance on how organisations might design their performance measurement systems to enhance employee engagement and performance.

Originality - Our study makes three contributions. First, we introduce a new theoretical framework based the organisational control theory providing a basis for future research. Second, through nine propositions we establish a causal relationship between performance measurement, performance management, employee engagement and performance. Third, we identify a gap in knowledge concerning design of organisational controls in the context of the process that is being managed.

Keywords: Performance measurement, employee engagement, action research, experiments 


\section{Introduction}

Since Johnson and Kaplan (1987) published Relevance Lost, performance measurement has gained popularity, with Neely (1999) identified over 3,600 articles between 1994 and 1996. Consequently a plethora of performance measurement frameworks emerged (Keegan et al., 1989; Kaplan and Norton, 2001; Bourne et al., 2000; Neely et al., 2002). Recently, performance measurement has been criticised with Johnson and Broms (2000) implying that a well-performing organisation does not need measures and Ghoshal (2005) criticising current management theories for emerging social and economic conditions. Hamel (2009) criticises the suitability of performance measurement theories and practices for modern organisations. Suggesting that the measurement and management of performance in organisations increases fear, reduces trust, promotes 'command and control' systems, diminishing employee engagement.

Grant (2008) argues that Hamel overstates such a radical shift in management thinking, but there is recognition of a democratic, open, participative and fear-free management being essential for the 21st century organisation (Wang, 2008; Danneels, 2008; Garvin et al, 2008). There is increasing emphasis on improving performance measurement systems and performance management practices to enhance employees' engagement levels and, ultimately, performance (Bourne et al, 2013; Sorenson, 2013). However, the interplay between performance measurement, performance management, employee engagement and performance remains poorly understood. Understanding this interplay is now considered critical for further development of the performance measurement theory (Bititci et al., 2012; Melnyk et al., 2013) and practice (Hamel, 2009; Franco-Santos et al., 2012). However, the difficulty of undertaking research in this area is also recognised (Bititci et al., 2012; Franco-Santos et al., 2012). For meaningful insights to emerge, longitudinal fine grained qualitative studies are required, through engaged scholarship (Van de Ven, 2007), with researchers immersed in the change process to theorise about this phenomenon. The research presented in this paper provides a unique opportunity to empirically investigate this interplay through longitudinal action research in two operational departments of a UK bank.

\section{Background}

The foundations of performance measurement lie in the organisational and management control theories emerging from general systems theory (Weiner, 1948; Bertalanffy, 1968). This is evident in Neely et al.'s (1995: 80) definition; "a performance measure is a metric used to quantify the efficiency and/or effectiveness of action".

Organisational control and management control theories also view an organisation as a dynamic entity operating in an environment constantly changing thus necessitating the basic structure of any control system: Measure, compare, analyse, correct and prevent (e.g., Tessier and Otley, 2012; Melnyk et al., 2013). However, organisations are complex systems and theories that surround organisational control, managerial control and performance measurement have evolved from related but parallel fields.

Research on organisational control dates back to Cyert and March (1963) and Child (1973). Others have built on these works and defined distinct approaches to organisational control (Ouchi, 1979). Recently authors such as Liu et al (2013) have continued to develop frameworks for organisational control. A common theme recognises two different types of organisational control, albeit using 
different terminologies to express these dimensions: Technical-control and social-control mechanisms (Child, 1973; Ouchi, 1979; Cardinal et al, 2004). Technical-control refers to rational, planned, bureaucratic and structural elements of the organisation. Whereas the social-control focus on emergent, cultural and behavioural aspects of the organisation.

Management control theories, instead, have been evolving from management accounting literature (Tessier and Otley, 2012). Rotch (1993: 191) suggests 'control is the process of assuring that the organisation does what the management wants done' and proposes a management control framework that comprises six key components (strategy, structure, performance measures, direction, motivation and incentives). Although he goes on to discuss the interrelationships between these components, he places particular importance on understanding the social aspects of its operation rather than focusing solely on rational aspects of its design. Simons (1994), in studying how managers use formal control systems for strategic change, identifies four levers of control: Belief systems that provide momentum and guidance (purpose, values, direction); boundary systems that allow creativity within defined limits (rules, guidelines, codes of practice); diagnostic systems that ensure important organisational goals are achieved (feedback, monitoring, review); interactive systems that focus attention on strategic uncertainties (managerial decisions). Tessier and Otley (2013) review Simons' (1994) levers of control model and propose a revised framework which places the technical and social dimensions of control as central concepts.

Performance measurement literature displays a similar path. According to Bititci et al. (2012) and Melnyk et al. (2013) it has evolved through performance measurement (what to measure) to performance management (how to use the measures to manage organisations' performance). In this context performance measurement is defined as the process (or processes) of setting goals, developing a set of performance measures, collecting, analysing, reporting, interpreting, reviewing and acting on performance data (Neely et al., 1995; Melnyk et al., 2013). From an organisational control perspective this definition aligns with the rational/technical dimension of organisational controls. On the other hand, performance management is defined as the cultural and behavioural routines that define how we use the performance measurement system to manage the performance of the organisation (Bititci, 2015). This definition aligns with the cultural/social-controls dimension of organisational control.

Actually, the performance measurement literature recognises that the performance management process must reinforce organisational learning (Davenport 2006; Upadhaya et al., 2014; McAdam et al. 2014) and that the role of behavioural and cultural factors are key to successful use of performance measurement systems (Bourne and Neely 2000; Franco and Bourne 2003; Garengo and Bititci 2007). Indeed, Bourne et al (2013) explicitly recognises the linkages between performance measurement, behaviours and engagement. However, these technical (performance measurement) and social (performance management) dimensions have not been conceptualised as two separate but interdependent dimensions of organisational control. Thus there has been little attempt to develop a theoretical framework for understanding the interplay between the technical-controls (performance measurement) and social-controls (performance management), and how this may influence employee engagement and performance.

As the theoretical focus of this paper is on performance measurement and management we treat employee engagement as an outcome. We recognise the vast body of literature around the concept, 
but refrain from being distracted by a detailed critique of this area and focus our review on its definition, measurement and antecedents. Macey et al. (2009: 4) define employee engagement as "employees feeling so engaged and energized that they give extra time and resources without management asking". Employee engagement often comprises cognitive, emotional and behavioural concepts (Saks, 2006: 602). While, a number of frameworks measure employee engagement (Saks, 2006) it is usually measured through two components, job engagement and organisational engagement. It is recognised that employee engagement affects performance (Chiva and Alegre, 2009; Tregaskis et al., 2013) but how measurement and management practices influence employee engagement is often neglected. What is commonly understood is factors such as a clear sense of purpose, autonomy, supportive learning environment, psychological safety and having the opportunity to specialise enhance engagement levels (Saks, 2006; Cartwright and Holmes, 2006; Garvin et al, 2008; Dollard and Bakker, 2010).

\section{Organisational Control Theory Lens}

Based on the above discussion the organisational control, management control and performance measurement theories agree that social and technical-controls co-exist; thus they need to be considered simultaneously (Cardinal et al, 2004; Bititci et al., 2012; Tessier and Otley, 2012). Our framework was influenced by works from the performance measurement and organisation studies fields. In the performance measurement literature there are conflicting views. On the one hand literature reports that organisations managed through measures perform better (de Waal, 2001). Conversely it is argued that linking performance measures with pay can intensify command and control practices resulting in lower engagement levels (Ittner and Larcker, 2003; Pink, 2009). Literature contains a number of classifications and taxonomies that explain the behaviour of individuals, groups and organisations. Specifically, Donaldson and Luo (2014) outline how Aston Studies grouped organisations as Weberian, Charismatic, Neo-liberal economic and Humanistic where the description of these organisation types demonstrate the concurrency between technical and social-controls. Based on this insight we have set the social and technical-controls as two separate but interrelated and complementary concepts. Here, we were interested in understanding how changes in the technical and social-controls impact one another and, ultimately, employee engagement and performance.

In terms of technical-controls, performance measurement includes activities such as: Developing metrics; target setting; collecting, analysing and reporting performance information; and, interpreting and assessing performance differentials. The literature also describes various performance measurement maturity levels ranging from ad-hoc, through adolescent and grown-up to mature (Wettstein and Kueng, 2002) with some formalised models (Van Aken et al., 2005; Garengo 2009). Speckbacher et al. (2003) reflects the technical maturity of performance measurement systems contained in other maturity models. They propose three levels of maturity, representing the three evolutionary phases of a performance measurement system. Type I comprises a balanced set of strategic measures. Type II is as Type I but includes an awareness of the cause-and-effect relationships within the measurement system. Type III is similar to Type II but also includes incentives that link with strategic objectives and plans. However, whilst pay for performance type schemes is considered sub-optimising, group or team based rewards that link to strategic outcomes are associated with more mature performance measurement systems (Eisenhardt, 1985; Ittner, 2008). It is also accepted that a mature performance measurement system 
would: Deploy the high level strategic measures to lower levels through local measures and targets (Atkinson et al., 1997; Bititci et al., 1997); ensure that managers with the right span of accountability and control are responsible for the metrics (Simons, 2013); report measures and their trends in an accessible manner (Barnes and Walker, 2010); and, exercise short interval control through frequent reviews of performance reports (Wilson, 2004).

Social-controls, are conceptualised as the cultural and behavioural routines that define how we use the performance measurement system to manage the performance of the organisation. Seen as a continuum of practices that spans from command and control to democratic and participative management. Command and control management comprises: specialisation and demarcation of work; job standardisation; prescribed activities and tight controls; internal competition; limited commitment to employees; reward and punishment (Podsakoff and Todor, 1985; Chenhall, 2003; Powely et al., 2004; Mohamed et al., 2004). Whereas democratic participative management comprises: job enrichment and multiskilling; autonomy and self-management with loose controls; participation and industrial democracy; psychological safety; appreciating differences and being open to new ideas; creating time for idea sharing and reflection (Carmeli et al., 2009; Carson et al., 2007; Wood and Wall, 2007; Poole et al., 2001).

Literature on employee engagement suggests a direct relationship between higher levels of employee engagement and organisational performance (Chiva and Alegre, 2009; Tregaskis et al., 2013). Furthermore, factors such as a clear sense of purpose, autonomy, a supportive learning environment and psychological safety enhance engagement levels of employees (Saks, 2006; Cartwright and Holmes, 2006; Garvin et al, 2008; Dollard and Bakker, 2010). Based on the discussion on organisational controls, the factors that serve to enhance employee engagement levels are largely associated with social-controls (Carson et al., 2007; Carmeli et al., 2009). This assertion leads us to the development of our theoretical framework where we conceptualised performance measurement and performance management, technical and social-controls, as two separate but interdependent dimensions of organisational control that are linked, either directly or indirectly, to employee engagement and performance. Figure 1 illustrates our theoretical framework, complete with characteristics that typify technical and social-control as discussed earlier in this section.

\section{Insert Figure 1 here}

Based on this theoretical framework a number of propositions can be developed. However, as our interest is the interplay between performance measurement, performance management, employee engagement and performance, the proposition that underpins our research is: An intervention made on the social-control dimension towards democratic and participative management is likely to have three different effects:

- First, we would expect to see some changes to the technical-controls (performance measurement systems). Our rationale behind this prediction is that all three bodies of literature (organisational control, management control and performance measurement) perceive the technical and social dimensions of organisational control as separate but closely interrelated. However, based on the extent literature, we could not predict the nature of the expected changes. 
- Second, we would expect to observe improvements in both organisational and job engagement elements of employee engagement but from the available literature we were not able to predict the exact nature of how this effect would emerge.

- Third, we would expect to observe improvements in performance as a result of the improved levels of employee engagement.

\section{Research Design}

An action research approach was adopted in two separate departments of the Bank, with a pilot and control group in each department. Our analysis compares the impact of the intervention in the social-control dimension on technical-controls, employee engagement and performance, between the pilot and control groups in department.

Action research is criticised for its lack of repeatability (Eden and Huxham, 1996) and reliance on the experience of the researchers (Coughlan and Coghlan, 2002). However, in this case, the opportunity to conduct action research based controlled experiments together with the following benefits outweighed its limitations. First, it allows observation of the impact of specific interventions (Eden and Huxham, 1996). Second, it empowers participants to contribute to the design of the intervention and analysis of the results (Coughlan and Coghlan, 2002; Burns et al., 2014). Third, it is suitable when theory is developed in incremental steps (Coughlan and Coghlan, 2002: 222). In this case we were able to explore our proposition by facilitating changes, monitoring and reflecting via an iterative and participative research process, maintaining dialogue with employees at various levels. Thus we observed the complex interplay between performance measurement, performance management, employee engagement and performance.

Our units of analysis were two departments of a UK bank (the Bank). In 2010 employee engagement was a group-wide strategic initiative. The academic team had an existing relationship with senior management who thought their approach to performance measurement was having a negative influence on engagement levels.

“... initially (2004) we focused on measuring and managing productivity but this did not work, productivity deteriorated, customer service got worst and people were miserable.... We then to focused more on customer service. This improved things a little but did not deliver the results we were looking for" (Head of Contact Centres).

"... I believe our business is about people, we have people serving customers...the real issue is that our people are demotivated... it never used to be like this, my feeling is that over the past ten years we put more and more measures and controls in place it feels like we are running a machine...people do not enjoy coming to work anymore...l think they feel like robots" (Operations Director).

Subsequently we were invited to undertake a "controlled experiment" with two distinctly different operational departments of the organisation.

\section{Context}

The Bank had implemented a balanced score card (BSC) in 2001. High level goals are deployed to departments, teams and individuals. The measures used achieve a balance between financial, 
customer, process and growth perspectives. Individual and team based scorecards are then used to inform annual reviews and incentives based on the overall performance of the bank. Visual displays of performance, targets and trends are widely used. Purpose-built software underpins the performance measurement system, with data collected and used to produce daily performance reports. There is clear awareness of the causal relationship between processes, customer satisfaction and financial results. Evidently the Bank had a well-developed, mature performance measurement system (i.e., technical-controls) used in a directive manner with prescribed activities and tight controls to create internal competition linking individual performance to reward and disciplinary routines (i.e., social-controls), positioning the bank in the top-left quadrant of our theoretical framework (Figure 1).

\section{The Intervention}

The intervention comprised of two action research cycles: Planning, action, monitoring and reflection (Coughlan and Coghlan, 2002), over four months. The teams (15 AMS and 12 MS) were split in to 'control' and 'pilot' groups. The pilot groups (eight AMS and six MS) were facilitated by the academic team, with no intervention by their management, to effect a change in the social-controls towards a more democratic and participative management. This required us to encourage the pilot groups to think differently about their jobs by asking 'How would you make your job better? How would you manage this department?' giving the pilot teams the autonomy for redesigning their jobs. The academic team was careful not to suggest any ideas, letting the changes emerge from the discussions amongst the team members, essentially working in a participative manner with the two pilot teams to help them develop their ideas. Once the changes were agreed it was the responsibility of the pilot teams to implement the changes. The intervention was cyclical and many changes were attempted but not implemented; throughout the two-cycles both pilot teams learned about constraints and what was achievable, e.g. in MS the team planned to implement a flexible working arrangement, but concluded that this would not be feasible due to the structure of the work. In another case, the team removed the targets but then concluded that having a target created a positive focus; thus reinstating the target. The changes were implemented by the team members themselves, and then operated for six months to allow the changes to embed. Throughout, the academic team was constantly in touch with the pilot teams but had no interaction with the control teams.

\section{Measuring performance}

The effect of the intervention on performance was assessed using the existing performance information used by the Bank. This was available at individual level, departmental level and the Bank was able to aggregate the performance information at pilot and control group level. Performance data consisted of productivity, quality errors and customer satisfaction metrics; this data were being collected before our interaction and carried on after our intervention was completed. We analysed the performance data for May-July 2010 as the 'before' data and for November 2010-April 2011 as the 'after' data to show any changes in performance between the pilot and control groups.

\section{Assessing employee engagement}

Employee engagement was already being assessed by the Bank using Saks' (2006) employee engagement approach. For our research, engagement data were collected at two distinct points, at 
the outset before the project announcement was made and eight months after implementation of the changes. The engagement survey used Saks' (2006) two main components of engagement (job engagement and organisational engagement) with each being associated with positive and negative statements. Respondents were asked to rate their agreement on a five-point Likert scale, ranging from strongly agree to strongly disagree. The engagement score for each employee was then aggregated according to the positive, neutral and negative scores to give engagement profiles for each individual. These data were then aggregated to develop group engagement profiles.

\section{Interview data}

Formal interviews were undertaken at the outset of the research and also eight months after the implementation. These were carried out with the team members in the pilot groups. Interviews were carried out in groups of three to four people lasting approximately 60 minutes. The initial interviews, undertaken in June 2010, asked the team members how they felt about their jobs, what they thought about customer satisfaction, how they felt with current performance measures and management processes and how they felt about their own engagement with the organisation. At the same time, six team leaders were also interviewed for their perception of the performance measures and the management process as well as what they thought influenced employee engagement. In April 2011 formal interviews were completed in the same format with the same team members, the questions were unchanged to allow for comparative analysis to be performed. The same group of team leaders were also interviewed using the same questions. These formal interviews were digitally recorded providing over 18 hours of recording.

In addition, the research team were in constant contact with the pilot teams over the 10 month period (four months for intervention, six months for bedding-in) where data were collected through informal conversations and observations, which were recorded in the research diary comprising of over 260 pages. Below is an overview of the research timeline.

- May 2010 Initial discussion between the academic team and the bank

- June $\mathbf{2 0 1 0}$ Initial interviews, engagement survey and review of performance metrics

- July 2010 Project announcement and selection of departments

- August 2010 to September 2010 Action research cycle 1 -Workshops with pilot teams, planning initial intervention and implementation (planning and action)

- September 2010 First evaluation with pilot teams (monitoring and reflection)

- September 2010 to November 2010 Action research cycle 2 -Workshops with pilot teams, planning and implementing final intervention (planning and action)

- October 2010 Interim evaluation and changes to intervention (monitoring and reflection)

- November 2010 Final evaluation of intervention (monitoring and reflection)

- November 2010 to March 2011 Pilots operational with bi-weekly (nine) reviews with pilot teams

- April 2011 Final Interviews, final engagement survey and review of performance metrics (monitoring and reflection)

\section{Data analysis}


The interview data were analysed through qualitative techniques. One of the difficulties faced with qualitative research is the vast amount of data that is collected; but the benefit of this is that the data has richness. We examined and manually coded the recordings and research notes to identify common themes. First order codes emerging from the data were developed. Concept maps were developed to establish the interaction between the changes and the emerging themes. Throughout we reviewed and refined themes and concept maps based on discussions with the pilot team and the senior management. By comparing the codes and themes emerging from the initial and final interviews, and our observations of the before and after practices, it became clear that the intervention in the social-control dimension resulted in changes in the technical-controls. First, the frequency by which performance is reviewed was changed from daily to weekly intervals, i.e. the interval of control (Wilson, 2004). Second, the organisational level at which performance was measured was moved from the individual to the team, i.e. the resolution of control (Harris et al. 1999; Li and Gatland, 1996). Third, practices that promote rivalry between team members destroying team working were removed. We refer to this phenomenon as the practices that promote internal competition.

To summarise, we used explorative action research to explore a phenomenon (Barrett et al., 2011). Our unit of analysis comprised of two independent departments of the Bank with pilot and control groups in each department. We achieved triangulation through interviews, survey data, performance data and researchers' observations. Our findings come from analysing data from: The engagement survey; performance data; interview data and research diary.

\section{Findings}

\section{Changes Made}

Table 1 summarises the main characteristics of the two pilot areas and changes that emerged from our intervention. In MS the interval of control moved from daily intervals to weekly intervals. The resolution of control remained unchanged at the individual level. The practice of publicly displaying individuals' performance in league tables was discontinued. In AMS the resolution of control changed from individuals to the team. The interval of control remained unchanged at daily intervals.

\section{Insert Table 1 here}

\section{Consequences of the Changes}

The intervention in the social-controls resulted in changes in the technical-controls creating significant change in the social dynamics of the pilot areas as illustrated by the quotes and implications summarised in Table 2 together with significant improvements in employee engagement and performance results. In contrast, the control areas show insignificant improvements (AMS) or a certain degree of deterioration (MS).

\section{Insert Table 2 here}

At the outset our view was that an intervention made on the social-control dimension towards democratic and participative management is likely to have three different effects: First, we expect to 
see some changes to the technical-controls; second, we expect to observe improvements in employee engagement levels; third, we expect to observe improvements in performance.

Our findings, illustrated in Figure 2, demonstrate that an intervention on the social-controls towards a more democratic and participative approach has led to changes in technical-controls by relaxing the interval and resolution of control as well as removing emphasis on internal competition, arguably a slight reduction in the maturity of performance measurement systems (Wilson 2004; Harris et al. 1999). This has resulted in improved employee engagement and performance. The literature implies that creating more autonomy and psychological safety will improve employee engagement and, indirectly, performance (Cartwright and Holmes, 2006; Hamel, 2009). These findings extend this line of argument by identifying interval of control, resolution of control and internal competition as central concepts by which the interplay between performance measurement, performance management, employee engagement and performance could be influenced.

\section{Insert Figure 2 here}

\section{Discussion}

The research design introduces a new theoretical framework that enables better conceptualisation between technical and social-controls in the context of performance measurement and management. We identify 'internal competition', 'interval of control' and 'resolution of control' as factors influencing engagement and performance as well as ascertaining an important gap concerning the design of organisational controls in the context of the process being managed.

Our findings suggests achieving an appropriate balance between the two dimensions of organisational control results in improved employee engagement and overall performance. This is enabled through a more supportive environment and team working. Our framework allows us to observe and examine this interplay in more detail than has previously been possible (e.g., Simons, 1994).

The Aston Programme looked at organisational structures and control mechanisms and found that as organisations become more mature, and inherently complex, bureaucracy is substituted for direct personal control by management. Thus managers exert "indirect control by job specialization, rules, standard procedures and documents" (Donaldson and Luo, 2014: 87). Our findings suggest that as performance measurement systems become more mature there is a tendency for technical-controls to dominate over social-controls, becoming less personal and more focused on the performance data. Previously in our case performance measurement was used primarily for summative assessment of performance (Pavlov and Bourne, 2011) to diagnose performance gaps (Kouferos et al., 2014) and evaluate individual performance (Van Veen-Dirks, 2010) rather than for formative assessment to encourage learning and growth (Black and Wiliam, 2009). Measurement was mainly used as a managerial tool largely ignoring engagement related outcomes (Tung et al., 2011).

Proposition 1 - Using performance measures for summative purposes rather than formative purposes encourages a more command and control type of social-control to emerge. 
Here, the intention was to intervene in the technical-control axis by introducing better measurement systems. However, without a purposeful intervention in the social-control axis the social-controls moved from participative to directive.

The relationship between performance measurement systems and performance has been a source of debate. Whilst some claim a positive relationship (de Waal, 2001) others disagree (Hamel, 2009; Johnson and Broms, 2000). As exemplified in our data, the interplay between performance measurement (technical-controls), performance management practices (social-controls) and employee engagement may explain this confusion. Bourne et al. (2013) highlight that performance measurement and HRM practices are inseparable, we would argue that it would be misleading to delineate the field as performance measurement versus HRM. As discussed in our first proposition, an intervention in the technical-controls to improve the maturity of performance measures resulted in the emergence of a more directive social-control. However, we have also demonstrated that an intervention in the social-controls towards more democratic and participative approach resulted in, arguably, a small reduction in the maturity of technical-controls, whilst delivering increased engagement and performance.

Proposition 2 - Performance implications of performance measurement is a function of the interplay between performance measurement (technical-controls), performance management practices (social-controls) and employee engagement.

Often, the motivation behind the use of performance measures effects the performance outcome. Suggesting that performance improvement interventions may be designed as technical and/or social interventions, raising a question over the appropriate balance for a given context. As demonstrated in our data, when the Bank was implementing performance measures at the outset it was delivered as a technical intervention, whereas our action research intervention was focused on the socialcontrol dimension.

Proposition 3 - Performance measurement and improvement interventions may be configured as social and/or technical interventions that can have a positive or negative impact on the intended outcome.

Koufteros et al. (2014) define the use of performance measures as either 'diagnostic'; to maintain, alter or justify patterns in organisational activity or as 'interactive'; to orchestrate organisational resources towards competitive advantage. They conclude that the purpose of performance measures has an influence on the performance of organisations, calling for further understanding of the effect of performance measurement on individual actors rather than organisations. Similarly, Franco-Santos et al. (2012) highlight the scarcity of research on the effects of performance measurement systems on employee attitudes and behaviours. Our study demonstrates the impact the balance between technical and social-controls had on employee attitudes (e.g., willingness to participate in group wide activities) and behaviours (e.g., lying with regard to performance data). Our model provides a framework for conceptualising such interactions between performance measures, how they are being used, and employees' behaviour.

Our findings show that changes in performance measurement and performance management practices do influence one another. Furthermore, they show that changes interval of control, resolution of control and practices that encourage internal competition have an influence on the 
behaviour of teams with performance measures. It appears that when measures are used to create internal competition between team members they encourage individualistic behaviours and destroy team spirit.

In our study, the intervention in the social axis created a more open and participative environment leading to small but fundamental changes to the technical-controls. This had an effect on peoples' behaviour with performance measures, ultimately impacting on employee engagement and overall performance. The point that emerges from this is the absence of a direct link between performance measurement and performance. It appears that the maturity of performance measurement systems is indirectly linked to performance through social-controls and engagement. Whilst performance measures provide relevant information on performance, their use (i.e., performance management) can serve to engage or disengage people from the overall performance of the organisation. It is evident that the practice of publicly displaying individual performance had created a form of internal competition, discouraging teamwork and encouraging individualistic behaviours.

Proposition 4 - An intervention in the social-control dimension towards a more democratic and participative managerial approach results in changes in technical-controls, eliminating practices that promote internal competition as well as relaxing interval and/or resolution of control.

Senior and Swailes (2007) describe characteristics of a team as shared aims, open expression of feelings, cooperation and trust. Characteristics that were missing in the original teams. Individualistic behaviours seem to encourage people to falsify data to make their performance appear better. In contrast, elimination of practices that promote internal competition encourages greater levels of teamwork and honest reporting of performance data.

Proposition 5 - Elimination of practices that encourage internal competition between team members encourages teamwork and trust, creating a more supportive culture, thus positively impacting on employee engagement and performance.

This explicates the relationship between technical-controls and social impact, a point previously mooted (Rotch, 1993; Mohamed et al., 2004; Garengo and Bititci, 2007; Tessier and Otely, 2012) thus extending the existing knowledge.

In MS the employees felt that the management focus on productivity was unbalanced with less emphasis on quality and customer service. This was largely driven by the obsession concerning volume sheets that had to be completed by each individual on a daily basis. Here, time spent helping a colleague was having a negative effect on an individual's performance, thus further encouraging individualism. The removal of practices promoting internal competition together with relaxation of the interval of control from daily to weekly intervals seemed to create a more relaxed environment where people felt less time pressure, were able to focus on "getting the job done right first time" and took on additional tasks previously undertaken by the team leaders. In short their jobs are enlarged. It appears that the weekly interval of control is more appropriate for the process that is being managed.

Proposition 6 - Relaxation of the interval of control to an appropriate time period absorbs the natural variation inherent in the process alleviating time pressure and promoting a more balanced focus on performance thus further encouraging team development. In turn, encouraging people to 
take on more complex tasks, leading to job enlargement with a positive impact on engagement and performance.

In the literature high resolution short interval control is often cited as good practice for managing performance improvements (Wilson, 2004). Whilst this may be true for certain organisational settings, our findings contradict this view.

In AMS the team members, with 14 years of average experience, felt that they were not being trusted to do their jobs. It was clear that the Volume Reports, where each employee had to account for every minute of their time, were generally disliked and removed as a result of the intervention; the resolution of control was also relaxed from the individual to the team whilst the interval of control remained unchanged at a daily level. Although the option of relaxing the interval of control from daily to weekly intervals was discussed, the team decided to maintain control at daily intervals due to service level agreements with customers. The removal of practices that encourage internal completion as well as relaxation of the resolution of control from individuals to the team resulted in: A feeling of empowerment; better balance between productivity, quality and customer service; reduced time pressures; and more time for support and training.

Proposition 7-Relaxation of the resolution of control removes time pressure and promotes a more balanced focus on performance, encouraging team development. In turn, encouraging people to take on more complex tasks leading to job enlargement positively impacts engagement and performance.

A common theme is the perception of time pressure. Both pilot groups felt that the time pressures were not so much of an issue as before. It appears that changes have resulted in more time being created. It is believed that some of this extra time is real, created as a result of elimination of volume sheets and reduction in failure demand. However, at least some of this extra time is psychological, created by the removal of time pressures "...productivity, quality and customer service improved... so people are doing more work in the same timeframe and they are saying that they have more time to help each other and be involved in wider activities" (Operations Manager).

Proposition 8 - Performance measurement and management practices that create time pressures, whilst improving technical-controls, create a feeling of tighter performance management practices (social-controls) with a negative impact on teamwork, engagement and performance.

Thus we propose that a performance measurement intervention could result in the perception of tightening social-controls towards a command and control approach. However, this tendency could be counteracted if the performance measurement intervention was supported by a purposeful social intervention. Although previous literature recognises this relationship (Bititci et al 2012; Tessier and Otley, 2012; Franco and Bourne 2003), our findings explicate their nature by identifying the factors that influence them.

Proposition 9 - A performance measurement intervention tightening technical-controls could inadvertently result in tightening of performance management practices (social-controls) with a negative impact on engagement and performance unless supported by a purposeful social intervention.

Also, the nature of the process being managed appears to have an impact on the design of the performance measurement system (technical-controls). In AMS, the customers' service level 
requirements meant control was maintained at daily intervals. In MS, relaxing the interval of control from daily to weekly intervals allowed the natural variation in the complexity of the tasks to be absorbed creating a more realistic control interval. This highlights a new area for investigation not previously addressed in existing performance measurement system design guidelines (Azzone et al., 1991; Neely et al., 2000).

Clearly, there is a relationship between characteristics of the process and design of the performance measurement system (Jaaskelainen, et al., 2014). It appears that a performance measurement system designed without due consideration to these characteristics could be counterproductive. Yet, the performance measurement literature recommends 'short interval control' (Wilson, 2004: 266) and high resolution of control (Kaplan and Norton, 20010). In contrast, our findings contradict this point. We argue that organisational controls have to be designed with due consideration to process characteristics. However, the performance measurement literature gives little guidance on how process characteristics affect design of performance measurement systems, particularly with respect to the interval and resolution of control. There is also little guidance on how performance should be reviewed, summative versus formative. Thus further research is required to investigate the impact of process characteristics on the design performance measurement systems and performance management practices.

\section{Conclusions}

Our findings make theoretical contributions to the field of performance measurement in a number of ways. Firstly, the field of performance measurement has been previously criticised for weak theoretical foundations (Neely, 1999; Bititci et al 2012; Choong, 2013). In this paper we propose theoretical framework positioning performance measurement (technical-controls) and performance management (social-controls) as complementary but separate concepts. We demonstrate the utility of the framework to understand the interplay between performance measurement, performance management, employee engagement and performance. We suggest that our framework provides a robust theoretical basis for future research into performance measurement and management.

Secondly, we establish a clear relationship between performance measurement, management practices, employee engagement and performance. Our study suggests that measures and targets do not have a negative impact on engagement because the measures and targets remained the same throughout the intervention. However, engagement seems to be impacted by the way these measures and targets are used. We identify 'internal competition', 'interval of control' and 'resolution of control' as three separate but related technical-control concepts that influence socialcontrols and, consequently, employee engagement.

Thirdly, we identify an important gap in knowledge concerning the design of organisational controls in the context of the process being managed. Specific guidance is needed on how to design performance measurement systems that account for the process characteristics that are being controlled.

In developing these contributions nine propositions have emerged from our discussions with implications to theory and practice. Having demonstrated the complex nature of the interplay, the key theoretical implication is that future research into performance measurement and management 
should consider the interaction and relationship between these concepts. Failing to do so is likely to provide incomplete insights and potentially conflicting results.

From a practical perspective due consideration should be given to the interplay between technicalcontrols, social-controls and employee engagement as well as the characteristics of the process that is being managed. This is particularly relevant when developing and implementing performance measurement systems, as not doing so may yield unexpected or unintended results. We believe that performance measurement interventions need to be accompanied by conscious interventions in the social-control dimension to prevent emergence of a command and control environment.

Concerning limitations, as majority of the literature that underpins the theoretical framework and our case study is based on empirical findings from commercial organisations operating in the western economies, our findings are relevant to similar organisations operating in similar context. Further, our findings and conclusions are limited to two cases from a single organisation. Additional fine grained, longitudinal, collaborative research is required to fully understand the interplay between performance measurement, performance management, employee engagement and performance in a wider range of organisational contexts. Nevertheless, a key strength of action research is that it enables the researcher to be immersed in the context and develop a first-hand understanding of the phenomenon under investigation. Thus, in our view, action research and engaged scholarship are particularly suitable for researching the interplay between performance measurement, performance management, employee engagement and performance.

Finally, our work contributes to the wider theory on performance measurement and provides insights into designing performance measurement systems to enhance employee engagement and performance.

\section{References}

Atkinson, A. A., Waterhouse, J. H., \& Wells, R. B. (1997). A stakeholder approach to strategic performance measurement. Sloan management review, 38, 25-38.

Azzone, G., Masella, C., \& Bertelè, U. (1991). Design of performance measures for time-based companies. International Journal of Operations \& Production Management, 11(3), 77-85.

Baker, G. (2000). The use of performance measures in incentive contracting. The American Economic Review, 90(2), 415-420.

Baker, W. E., \& Sinkula, J. M. (1999). The synergistic effect of market orientation and learning orientation on organizational performance. Journal of the academy of marketing science, 27(4), 411-427.

Barnes, C., \& Walker, R. (2010). Improving corporate communications: Lean Six Sigma science has broad reach. Journal of Business Strategy, 31(1), 23-36.

Barratt, M., Choi, T. Y., \& Li, M. (2011). Qualitative case studies in operations management: Trends, research outcomes, and future research implications. Journal of Operations Management, 29(4), 329-342.

Bertalanffy, L. v. (1968). General system theory: Foundations, development, applications: Braziller. New York.

Bititci, U. S. (2015). Managing Business Perfromance : The Science and The Art : John Wiley \& Sons. Chichester.

Bititci, U., Garengo, P., Dörfler, V., \& Nudurupati, S. (2012). Performance Measurement: Challenges for Tomorrow*. International Journal of Management Reviews, 14(3), 305-327. 
Bititci, U. S., \& Carrie, A. S. (1998). Strategic management of the manufacturing value chain (Vol. 2): Springer.

Bititci, U. S., Carrie, A. S., \& McDevitt, L. (1997). Integrated performance measurement systems: a development guide. International Journal of Operations \& Production Management, 17(5), 522-534.

Black, P., \& Wiliam, D. (2009). Developing the theory of formative assessment. Educational Assessment, Evaluation and Accountability (formerly: Journal of Personnel Evaluation in Education), 21(1), 5-31.

Bourne, M., and Neely, A. . (2000). Why performance measurement interventions succeed and fail. Paper presented at the The 2nd International Conference on Performance Measurement, Cambridge.

Bourne, M., Mills, J., Wilcox, M., Neely, A., \& Platts, K. (2000). Designing, implementing and updating performance measurement systems. International Journal of Operations \& Production Management, 20(7), 754-771.

Bourne, M., Pavlov, A., Franco-Santos, M., Lucianetti, L., \& Mura, M. (2013). Generating organisational performance: The contributing effects of performance measurement and human resource management practices. International Journal of Operations \& Production Management, 33(11/12), 1599-1622.

Burns, D., Hyde, P., Killett, A., Poland, F., \& Gray, R. (2014). Participatory Organizational Research: Examining Voice in the Co-production of Knowledge. British Journal of Management, 25(1), 133-144.

Cardinal, L. B., Sitkin, S. B., \& Long, C. P. (2004). Balancing and rebalancing in the creation and evolution of organizational control. Organization Science, 15(4), 411-431.

Carmeli, A., Brueller, D., \& Dutton, J. E. (2009). Learning behaviours in the workplace: The role of high-quality interpersonal relationships and psychological safety. Systems Research and Behavioral Science, 26(1), 81-98.

Carson, J. B., Tesluk, P. E., \& Marrone, J. A. (2007). Shared leadership in teams: An investigation of antecedent conditions and performance. Academy of management Journal, 50(5), 12171234.

Cartwright, S., \& Holmes, N. (2006). The meaning of work: The challenge of regaining employee engagement and reducing cynicism. Human Resource Management Review, 16(2), 199-208.

Chenhall, R. H. (2003). Management control systems design within its organizational context: findings from contingency-based research and directions for the future. Accounting, organizations and society, 28(2), 127-168.

Child, J. (1973). Strategies of Control and Organizational Behavior. Administrative Science Quarterly, $18(1)$.

Chiva, R., \& Alegre, J. (2009). Organizational Learning Capability and Job Satisfaction: an Empirical Assessment in the Ceramic Tile Industry*. British Journal of management, 20(3), 323-340.

Choong, K. K. (2013). Has this large number of performance measurement publications contributed to its better understanding? A systematic review for research and applications. International Journal of Production Research(ahead-of-print), 1-24.

Coughlan, P., \& Coghlan, D. (2002). Action research for operations management. International Journal of Operations \& Production Management, 22(2), 220-240.

Cyert, R. M., \& March, J. G. (1963). A behavioral theory of the firm. Englewood Cliffs, NJ, 2.

Danneels, E. (2008). Organizational antecedents of second-order competences. Strategic Management Journal, 29(5), 519-543.

Davenport, T. H. (2006). Competing on analytics. Harvard Business Review, 84(1), 98.

de Waal, A., (2001). Power of performance management: How leading compaies create sustained value, John Wiley and Sons, New York. 
Dollard, M. F., \& Bakker, A. B. (2010). Psychosocial safety climate as a precursor to conducive work environments, psychological health problems, and employee engagement. Journal of Occupational and Organizational Psychology, 83(3), 579-599.

Donaldson, L., \& Luo, B. N. (2014). The Aston Programme Contribution to Organizational Research: A Literature Review. International Journal of Management Reviews, 16(1), 84-104.

Eden, C., \& Huxham, C. (1996). Action research for management research. British Journal of management, $7(1), 75-86$.

Eisenhardt, K. M. (1985). Control: Organizational and economic approaches.Management science, 31(2), 134-149.

Fitzgerald, L., Brignall, S., Silvestro, R., Voss, C., \& Robert, J. (1991). Performance measurement in service businesses: Chartered Institute of Management Accountants London.

Franco-Santos, M., \& Bourne, M. (2003). Factors that play a role in "managing through measures". Management Decision, 41(8), 698-710.

Franco-Santos, M., Lucianetti, L., \& Bourne, M. (2012). Contemporary performance measurement systems: A review of their consequences and a framework for research. Management Accounting Research, 23(2), 79-119.

Garengo, P. (2009). A performance measurement system for SMEs taking part in quality award programmes. Total Quality Management, 20(1), 91-105.

Garengo, P., \& Bititci, U. (2007). Towards a contingency approach to performance measurement: an empirical study in Scottish SMEs. International Journal of Operations \& Production Management, 27(8), 802-825.

Garvin, D. A., Edmondson, A. C., \& Gino, F. (2008). Is yours a learning organization? Harvard Business Review, 86(3), 109.

Ghoshal, S. (2005). Bad management theories are destroying good management practices. Academy of Management Learning \& Education, 4(1), 75-91.

Grant, R. M. (2008). The future of management: Where is Gary Hamel leading us? Long Range Planning, 41(5), 469-482.

Hamel, G. (2009). Moon shots for management. Harvard Business Review, 87(2), 91-98.

Harris, T.J., Seppala, C.T. and Desborough, L.D. (1999). A review of performance monitoring and assessment techniques for univariate and multivariate control systems. Journal of Process Control, 9(1), pp.1-17.

Ittner, C. D. (2008). Does measuring intangibles for management purposes improve performance? A review of the evidence. Accounting and Business Research, 38(3), 261-272.

Ittner, C. D., \& Larcker, D. F. (2003). Coming up short on nonfinancial performance measurement. Harvard business review, 81(11), 88-95.

Jääskeläinen, A., Laihonen, H., \& Lönnqvist, A. (2014). Distinctive features of service performance measurement. International Journal of Operations \& Production Management, 34(12), 14661486.Johnson, H. T., \& Bröms, A. (2000). Profit beyond measure. New York ao: The free press. -2000 .

Johnson, H. T., \& Broms, A. (2000). Profit beyond measure: Extraordinary results through attention to work and people. Simon and Schuster.

Johnson, H. T., \& Kaplan, R. S. (1987). Relevance lost. Boston: Harvard Business School Press

Kaplan, R. S., \& Norton, D. P. (2001). Transforming the balanced scorecard from performance measurement to strategic management: Part I. Accounting horizons, 15(1), 87-104.

Keegan, D. P., Eiler, R. G., \& Jones, C. R. (1989). Are your performance measures obsolete? Management accounting, 70(12), 45-50.

Koufteros, X., Verghese, A. J., \& Lucianetti, L. (2014). The effect of performance measurement systems on firm performance: A cross-sectional and a longitudinal study. Journal of Operations Management, 32(6), 313-336.

Li, H.X. and Gatland, H.B. (1996). Conventional fuzzy control and its enhancement. Systems, Man, and Cybernetics, Part B: Cybernetics, IEEE Transactions on, 26(5), pp.791-797. 
Liu, L., Borman, M., \& Gao, J. (2013). Delivering complex engineering projects: Reexamining organizational control theory. International Journal of Project Management.

Macey, W. H., Schneider, B., Barbera, K. M., \& Young, S. A. (2009). Employee engagement: Tools for analysis, practice, and competitive advantage: Wiley-Blackwell.

McAdam, R., \& Bailie, B. (2002). Business performance measures and alignment impact on strategy: the role of business improvement models. International Journal of Operations \& Production Management, 22(9), 972-996.

McAdam, R., Hazlett, S. A., \& Galbraith, B. (2014). The role of performance measurement models in multi level alignment: An exploratory case analysis in the utilities sector. International Journal of Operations \& Production Management, 34(9), 1153-1183.

Melnyk, S. A., Bititci, U., Platts, K., Tobias, J., \& Andersen, B. (2014). Is performance measurement and management fit for the future?. Management Accounting Research, 25(2), 173-186.

Miles, M. B., \& Huberman, A. M. (1994). Qualitative data analysis: An expanded sourcebook: Sage.

Mohamed, M., Stankosky, M., \& Murray, A. (2004). Applying knowledge management principles to enhance cross-functional team performance. Journal of Knowledge Management, 8(3), 127142.

Neely, A. (1999). The performance measurement revolution: why now and what next? International Journal of Operations \& Production Management, 19(2), 205-228.

Neely, A., Gregory, M., \& Platts, K. (1995). Performance measurement system design: a literature review and research agenda. International Journal of Operations \& Production Management, 15(4), 80-116.

Neely, A., Mills, J., Platts, K., Richards, H., Gregory, M., Bourne, M., \& Kennerley, M. (2000). Performance measurement system design: developing and testing a process-based approach. International Journal of Operations \& Production Management, 20(10), 11191145.

Neely, A. D., Bourne, M., Mills, J., Platts, K., Richards, A., \& Gregory, M. (2002). Strategy and performance: getting the measure of your business: Cambridge University Press.

Otley, D. (1999). Performance management: a framework for management control systems research. Management Accounting Research, 10(4), 363-382.

Otley, D., Broadbent, J., \& Berry, A. (1995). Research in management control: an overview of its development. British Journal of management, 6(s1), S31-S44.

Ouchi, W. G. (1979). A conceptual foundation for the design of organizational control mechanisms. Management Science, 25, 833-848.

Pavlov, A., \& Bourne, M. (2011). Explaining the effects of performance measurement on performance: An organizational routines perspective. International Journal of Operations \& Production Management, 31(1), 101-122.

Pink, D. (2009). Drive: The Surprising Truth About What Motivates Us. New York: Penguin Group, Inc, 138, 240.

Podsakoff, P. M., \& Todor, W. D. (1985). Relationships between leader reward and punishment behavior and group processes and productivity. Journal of Management, 11(1), 55-73.

Poole, M., Lansbury, R., \& Wailes, N. (2001). A comparative analysis of developments in industrial democracy. Industrial Relations: A Journal of Economy and Society, 40(3), 490-525.

Powley, E. H., Fry, R. E., Barrett, F. J., \& Bright, D. S. (2004). Dialogic democracy meets command and control: Transformation through the appreciative inquiry summit. The Academy of Management Executive, 18(3), 67-80.

Rotch, W. (1993). Management Control Systems: One View of Components and Their Interdependence1. British Journal of management, 4(3), 191-203.

Saks, A. M. (2006). Antecedents and consequences of employee engagement. Journal of Managerial Psychology, 21(7), 600-619.

Senior, B., \& Swailes, S. (2007). Inside management teams: Developing a teamwork survey instrument. British Journal of Management, 18(2), 138-153. 
Simons, R. (1994). How new top managers use control systems as levers of strategic renewal. Strategic Management Journal, 15(3), 169-189.

Simons, R. (2013). Levers of control: How managers use innovative control systems to drive strategic renewal. Harvard Business Press.

Sorenson, S. (2013). How employee engagement drives growth. Gallup business journal. June 2013.

Speckbacher, G., Bischof, J., \& Pfeiffer, T. (2003). A descriptive analysis on the implementation of balanced scorecards in German-speaking countries. Management Accounting Research, 14(4), 361-388.

Tessier, S., \& Otley, D. (2012). A conceptual development of Simons' Levers of Control framework. Management Accounting Research, 23(3), 171-185.

Tregaskis, O., Daniels, K., Glover, L., Butler, P., \& Meyer, M. (2013). High Performance Work Practices and Firm Performance: A Longitudinal Case Study. British Journal of management, 24(2), 225-244.

Tung, A., Baird, K., \& Schoch, H. P. (2011). Factors influencing the effectiveness of performance measurement systems. International Journal of Operations \& Production Management, 31(12), 1287-1310.

Upadhaya, B., Munir, R., \& Blount, Y. (2014). Association between performance measurement systems and organisational effectiveness. International Journal of Operations \& Production Management, 34(7), 853-875.

Van Aken, E. M., Letens, G., Coleman, G. D., Farris, J., \& Van Goubergen, D. (2005). Assessing maturity and effectiveness of enterprise performance measurement systems. International Journal of Productivity and Performance Management, 54(5/6), 400-418.

Van de Ven, A. H. (2007). Engaged scholarship: a guide for organizational and social research: a guide for organizational and social research. Oxford University Press.

Van Veen-Dirks, P. (2010). Different uses of performance measures: The evaluation versus reward of production managers. Accounting, Organizations and Society, 35(2), 141-164

Wang, C. L. (2008). Entrepreneurial orientation, learning orientation, and firm performance. Entrepreneurship Theory and Practice, 32(4), 635-657.

Weiner, N. (1948). Cybernetics: New York: Wiley.

Wettstein, T., \& Kueng, P. (2002). A maturity model for performance measurement systems. Management Information Systems, 113-122.

Wilson, A. (2004). How process defines performance management. International Journal of Productivity and Performance Management, 53(3), 261-267.

Wood, S. J., \& Wall, T. D. (2007). Work enrichment and employee voice in human resource management-performance studies. The International Journal of Human Resource Management, 18(7), 1335-1372. 
- High degree of awareness of the causal relationship

- Strategic measures are deployed to lower levels,

- Targets and incentives link to strategic objectives

- Managers with the right span of accountability and control

- Measures and their trends are reported in an accessible manner

- Regular and frequent performance revicws

Short interval control

- Specialisation and demarcation of work

- Job standardisation

- Prescribed activities and tight controls

- Internal competition

- Limited commitment to employees

- Reward and punishment
Technical Control

Performance Measurement

High Maturity Performance Management \begin{tabular}{l|c}
$\begin{array}{l}\text { Command } \\
\text { and Control }\end{array}$ & $\begin{array}{c}\text { Democratic and } \\
\text { Participative }\end{array}$ \\
\hline
\end{tabular} and Control

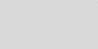

- Little awareness of the causal relationship

- Strategic measures are NOT deployed to lower levels,

- Targets and incentives NOT link to strategic objectives

- Managers do not have right span of accountability and control

- Measures and their trends are not reported and not accessible

- Performance reviews - not regular or in response to an emergency

\section{Figure 1. Theoretical framework with characteristics that typify technical and social-control}




\section{Area \\ Function \\ Responsible for receiving and processing of mortgage}

applications via an electronic system

KPIs

- Productivity - number of applications processed by each unit of resource

- Quality - the rigour by which each application is assessed

- Customer satisfaction - complaints received

15 Employees

- $1 \times$ manager

MS $\quad \begin{aligned} & \text { - } 3 x \text { team leader } \\ & \text { - } 12 x \text { employees }\end{aligned}$

Experience level

6 years of average experience with an average age of 28

Education

Team and team leader with predominantly secondary education. Graduate manager.

Male/Female ratio

$8 / 7$

Ethnicity

14 White UK

1 Asian UK (employee)

\section{Function}

Responsible for authenticating cheques received that is

largely a manual process

KPIs

- Productivity - number of cheques processed by each unit of resource

- Quality - the rigour by which each cheque is authenticated

- Customer satisfaction - complaints received

19 Employees

- 1 x manager

AMS $-3 x$ team leader

- $15 \mathrm{x}$ employees

Experience level

14 years of average experience with an average age of 42 Education

Team and team leader with predominantly secondary education. Graduate manager.

Male/Female ratio

$8 / 11$

Ethnicity

19 White UK

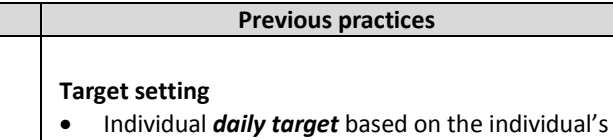

- Individual daily target based on the individual's previous performance - set by team leader

\section{Use of targets}

- At the end of each shift each person completes a detailed task report which comprises of each task and time taken (e.g., answered telephone call-3.21mins)

- The task reports are submitted to the team leader who manually enters the data into the performance assessment system which gives each agent a productivity score as a percentage of the team average (e.g., 120\%)

- The Team leader enters the individual score on to the task report and returns the report back to the agent on a daily basis against the daily targets

- The Individual reports are publicly posted on the team information boards

\section{Target setting}

- Have an agreed individual daily target based on the individual's previous performance and load required

\section{Use of targets}

- At the end of each shift each agent completes a detailed task report comprised of each task and time taken (e.g., answered telephone call 3.21mins)

- The task reports are submitted to the team leader who manually enters the data into the performance assessment system which gives each agent a productivity score as a percentage of the team average (e.g., 120\%)

- The team leader enters the individual score on to the task report and returns the report back to the agent
Target setting

Individual weekly target based on the individual's previous performance - set by team leader

Use of targets

- At the end of each shift each person completes a detailed task report which comprises of each task and time taken (e.g., answered telephone call-3.21mins)

- The task reports are submitted to the team leader who manually enters the data into the performance assessment system which gives each agent a productivity score as a percentage of the team average (e.g., 120\%)

- The Team leader enters the individual score on to the task report and returns the report back to the agent on a weekly basis against the weekly targets

- The Individual reports are no longer publicly posted on the team information boards

\section{Target setting}

- Have an agreed daily target for the team rather than the individual based on the load required Use of targets

- Performance information is collected at team level and is no longer collected at individual level

- Performance assessment system is no longer used and no productivity score is given to individuals or teams

- Task report is no longer used
- Significant change moving the interval of control from daily to weekly

- No change

- No change

- Significant change moving the interval of control from daily to weekly

- Significant change as individuals' performances are no longer exposed

Table 1. Technical changes that emerged from the social intervention

Significant change across the entire process where daily targets are still set at individual level but these are not monitored. Instead, performance information is collected at the team level, i.e. the resolution of control moves from individuals to the team 


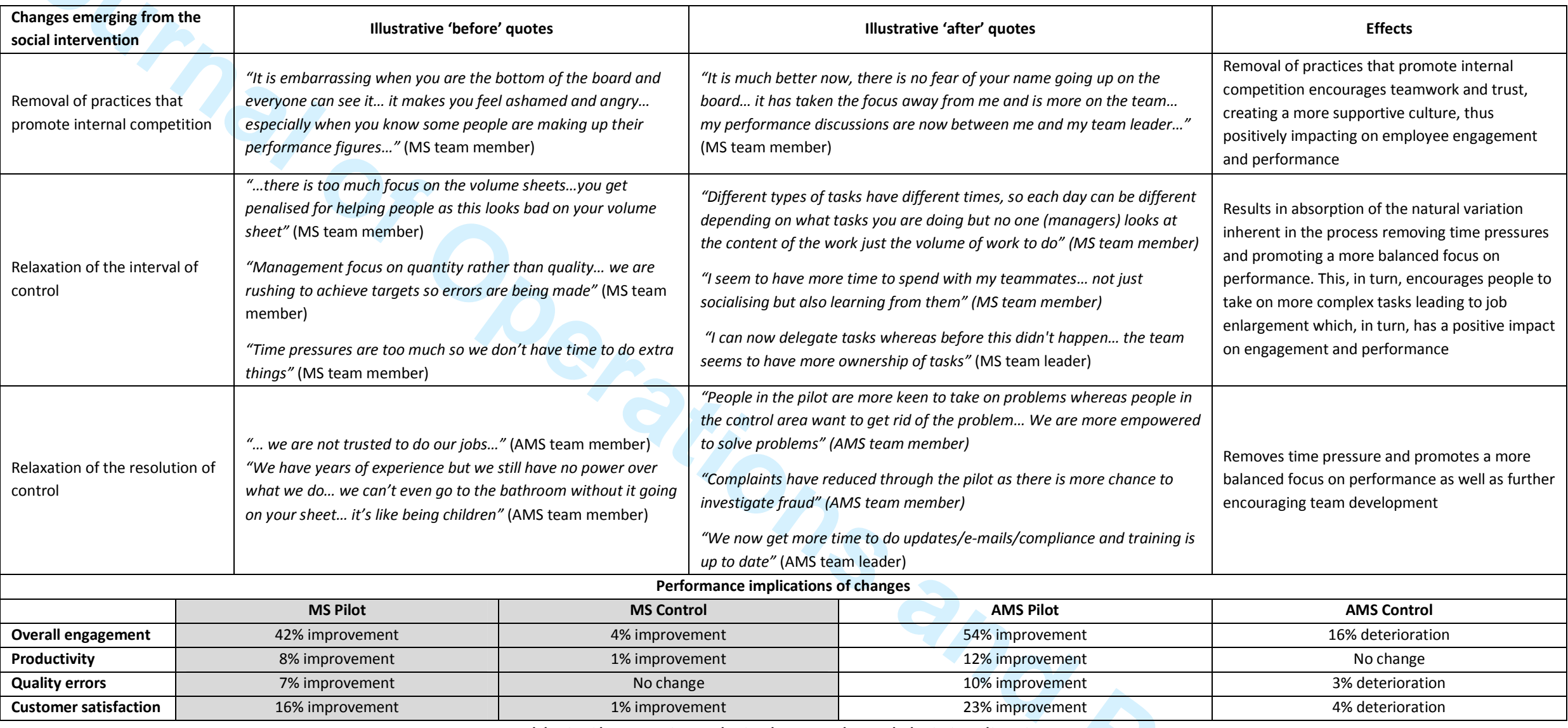

Table 2. Changes in technical-controls and their implications 


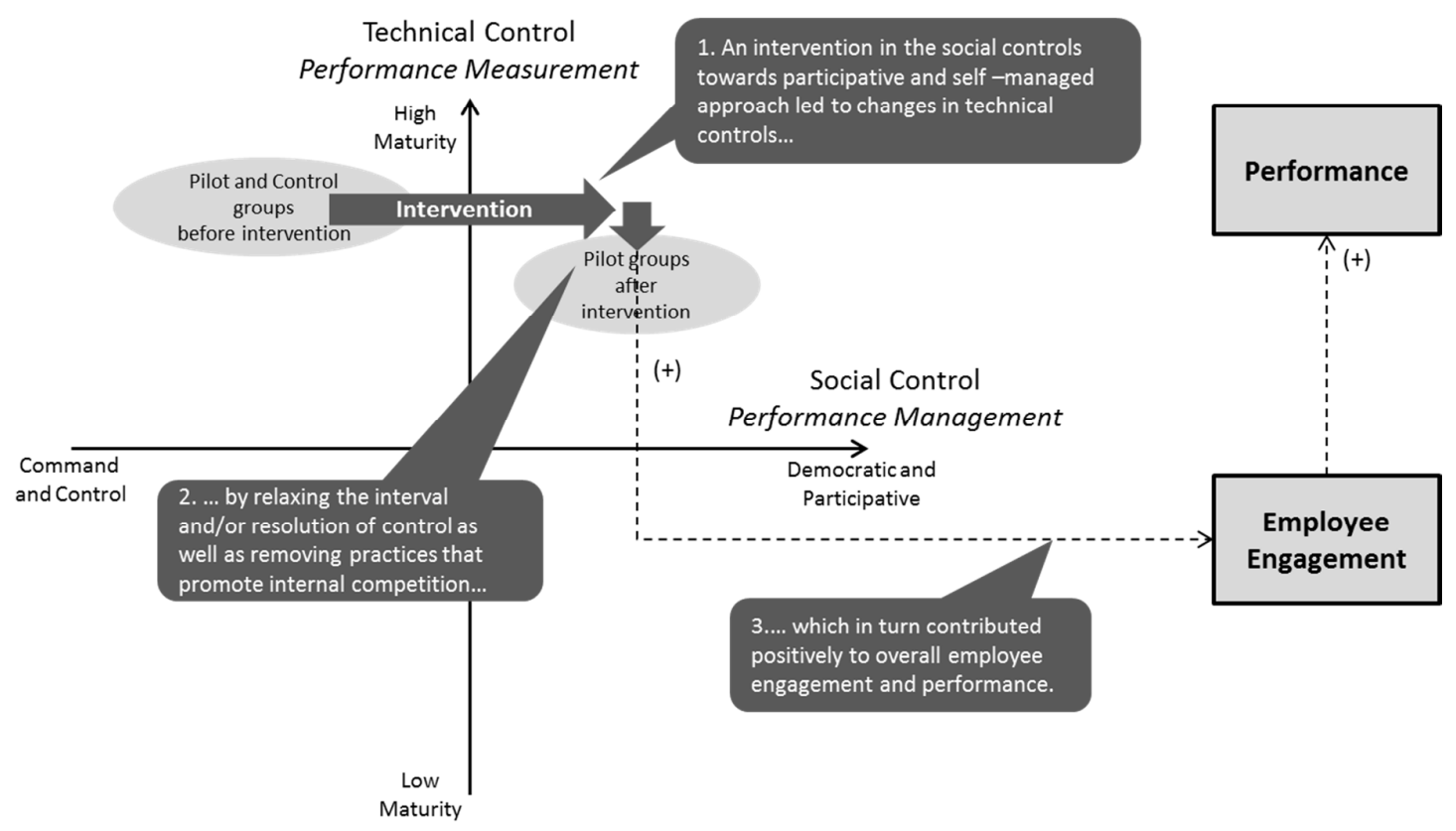

Figure 2. The interplay between performance management, performance measurement, employee engagement and performance 